Check for updates

Cite this: RSC Adv., 2017, 7, 26194

\title{
Thermal conductivity of multilayer dielectric films from molecular dynamics simulations
}

\author{
Liang Chen, ${ }^{\text {ab }}$ Niru Kumari, ${ }^{c}$ Shuangtao Chen $^{\mathrm{a}}$ and Yu Hou (D)*a
}

Reducing heat dissipation across nanometer-thick dielectrics is critically important for the self-heating behavior of nanoelectronic devices such as phase change memory. In this paper, we perform molecular dynamics simulations to study the thermal conductivity of multilayer dielectric films consisting of $\mathrm{SiO}_{2}$ and $\mathrm{Al}_{2} \mathrm{O}_{3}$. We show that the thermal conductivity of $\mathrm{SiO}_{2} / \mathrm{Al}_{2} \mathrm{O}_{3}$ multilayer structures can be significantly reduced as compared to that of the bulk dielectrics. The thermal conductivity calculations of crystalline and amorphous multilayer structures with different period thicknesses are presented as well as the size effects. The results show the thermal transport across the crystalline $\mathrm{SiO}_{2} / \mathrm{Al}_{2} \mathrm{O}_{3}$ multilayer structures is dominated by diffuse interface scattering between thin films, while the internal phonon-phonon scattering dominates the thermal conductivity of amorphous multilayer structures. Thickness dependence are observed for the crystalline multilayer dielectric structures but not in the amorphous structures, which can be attributed to the phonon localization by the lattice termination/deformation at interfaces between crystalline films.

Received 20th March 2017 Accepted 1st May 2017

DOI: $10.1039 / \mathrm{c} 7 \mathrm{ra0} 3275 \mathrm{~g}$

rsc.li/rsc-advances the dielectrics. Several studies have been conducted to reduce the heat loss through electrodes. ${ }^{7}$ Using electrode materials with low thermal conductivity, an effective reduction of reset current has been achieved which also improves the reliability and cycling endurance. ${ }^{8-11}$ Recently, multilayer dielectric films were proposed as the surrounding dielectric of PCM cells, and the steady-state Joule-heating measurements showed a promising reduction in their thermal conductivity compared to $\mathrm{SiO}_{2}{ }^{12}$ In PCM devices, reducing the thickness of dielectrics is preferred in order to make high-density arrays with high storage capacity. However, an effective thermal insulation of the PCM cell requires sufficiently thick dielectrics with high thermal resistance. The proper thermal design of the PCM requires a comprehensive understanding of the thermal transport across the dielectric structures as well as the dependence of thermal conductivity on structural parameters.

The thermal conductivity of alternating material layers, namely superlattices, has been extensively studied for semiconductor materials, ${ }^{13-16}$ e.g. Si/Ge, GaAs/AlAs, $\mathrm{Bi}_{2} \mathrm{Te}_{3} / \mathrm{Sb}_{2} \mathrm{Te}_{3}$, and simple Lennard-Jones solids. ${ }^{17,18}$ In those studies, the bulk materials have relatively high thermal conductivity as well as long phonon mean free path (MFP). The layer thickness is comparable to the phonon MFP, and the thermal transport in cross-plane direction can be ballistic within the layers. As a result, the phonon scattering at interfaces dominates the thermal transport while the phonon-phonon scattering within the layers becomes insignificant. ${ }^{19}$ Since the thermal boundary resistance (TBR) from a large number of interfaces plays a predominant role in the thermal transport of superlattice, the reduction its thermal conductivity can be achieved by
${ }^{a}$ School of Energy and Power Engineering, Xi'an Jiaotong University, Xi'an, Shaanxi 710049, China.E-mail: yuhou@mail.xjtu.edu.cn

${ }^{b} X i$ 'an Jiaotong University SuZhou Academy, Su Zhou, Jiangsu 215123, China

${ }^{c} H P$ Labs, Palo Alto, CA, USA 
increasing the interface density or equivalently reducing the layer thickness. In multilayer structures consisting of alternating dielectric materials (e.g. $\mathrm{SiO}_{2}$ and $\mathrm{Al}_{2} \mathrm{O}_{3}$ ), the contribution of interface scattering and internal scattering and the thermal conductivity dependence on layer thickness need further study, especially when considering the phonon MFP in low-thermalconductivity dielectric materials is relatively small. ${ }^{\mathbf{2 0}}$

In this work, we investigate the thermal transport across multilayer dielectric films consisting of $\mathrm{SiO}_{2}$ and $\mathrm{Al}_{2} \mathrm{O}_{3}$ in different layer thickness and total number of layers. Both crystalline and amorphous structures are considered. Nonequilibrium molecular dynamics (NEMD) simulations are performed to determine the thermal conductivity of $\mathrm{SiO}_{2} / \mathrm{Al}_{2} \mathrm{O}_{3}$ stacks with $4 \mathrm{~nm} \mathrm{SiO}{ }_{2}+2 \mathrm{~nm} \mathrm{Al}_{2} \mathrm{O}_{3}$ and $2 \mathrm{~nm} \mathrm{SiO}_{2}+1 \mathrm{~nm} \mathrm{Al}_{2} \mathrm{O}_{3}$, respectively. The total thickness of the stacks ranges from 12 to $68 \mathrm{~nm}$. The thermal conductivity of bulk $\mathrm{SiO}_{2}$ and $\mathrm{Al}_{2} \mathrm{O}_{3}$ are also presented as well as the thermal boundary conductance between $\mathrm{SiO}_{2}$ and $\mathrm{Al}_{2} \mathrm{O}_{3}$. The thermal conductivity from direct MD prediction is compared with the analytical estimation by combing the thermal resistance of layers and interfaces. The comparison shows different trends for the crystalline and amorphous multilayer structures. TBR contribution and thickness dependence are observed for the crystalline multilayer dielectric structures rather than the amorphous multilayer dielectric structures. The lattice dynamics calculations and localization mode analysis further reveal the phonon localization is responsible for the decrease of thermal conductivity of crystalline multilayer structures with reduced layer thickness. The present study will provide insights to understand the mechanism of thermal transport of multilayer structures of few-nanometer-thick dielectric films and to engineer the surrounding dielectrics for enhanced thermal insulation of PCM devices.

\section{Models and computational methods}

In this paper, BKS potential model ${ }^{\mathbf{2 1}}$ with Matsui's parameterization $^{22}$ is employed as the interatomic potential for all the calculations. The parameterization by Matsui shows good reliability and transferability for $\mathrm{CaO}-\mathrm{MgO}-\mathrm{Al}_{2} \mathrm{O}_{3}-\mathrm{SiO}_{2}$ system, and it has been verified against the lattice structures and bulk moduli. The BKS potential used in present work has the following form.

$$
V_{i j}=q_{i} q_{j} / r_{i j}+A\left(B_{i}+B_{j}\right) \exp \left(\frac{D_{i}+D_{j}-r_{i j}}{B_{i}+B_{j}}\right)-\frac{C_{i} C_{j}}{r_{i j}{ }^{6}}
$$

where $V_{i j}$ is the total interatomic potential between atoms $i$ and $j$. $r_{i j}$ is the interatomic distance between atoms $i$ and $j . q$ is the charge peculiar of the kind of ion $i$. The charge of $\mathrm{O}$ ions in $\mathrm{SiO}_{2} /$ $\mathrm{Al}_{2} \mathrm{O}_{3}$ system is -0.945 . The charges of $\mathrm{Si}$ and $\mathrm{Al}$ ions are 1.89 and 1.4175 , respectively, which can make the system neutral according to the composition ratio. $A, B$ and $C$ are the energy parameters. The three terms at the right hand side represent the Coulomb interaction, the Pauli repulsion energy, and the attractive van der Waals interaction, respectively.
The optimized lattice constants for crystalline $\mathrm{SiO}_{2}$ ( $\alpha$-quartz) and $\mathrm{Al}_{2} \mathrm{O}_{3}$ (corundum) are $4.91 \AA$ and $4.76 \AA$ in $a-b$ plane, respectively. An initial lattice constant of $4.91 \AA$ is used for $\mathrm{SiO}_{2} /$ $\mathrm{Al}_{2} \mathrm{O}_{3}$ structures to prepare the multilayer structure with a periodic boundary condition in the plane direction perpendicular to the heat transfer. The $a-b$ plane is used as the cross section to form the interface with dimensions of $2.47 \mathrm{~nm} \times 2.49 \mathrm{~nm}$. Slabs of crystalline lattices of each material are first generated with the conventional unit cells, e.g. $\mathrm{SiO}_{2}$ slabs of thickness of $4.1 \mathrm{~nm}$ and $1.9 \mathrm{~nm}$, and $\mathrm{Al}_{2} \mathrm{O}_{3}$ slabs of thickness of $2.6 \mathrm{~nm}$ and $1.3 \mathrm{~nm}$. The crystalline multilayer structures are formed by joining the crystalline slabs together, denoted by $4 \mathrm{~nm}-\mathrm{SiO}_{2} / 2$ $\mathrm{nm}-\mathrm{Al}_{2} \mathrm{O}_{3}$ and $2 \mathrm{~nm}-\mathrm{SiO}_{2} / 1 \mathrm{~nm}-\mathrm{Al}_{2} \mathrm{O}_{3}$ as shown in Fig. 1.

In order to prepare the samples of amorphous multilayer structures, the amorphous slab of each material is first obtained starting from its crystalline lattice. A slab of crystalline lattice is generated, and a series of MD simulations are performed in order to obtain the amorphous structure. The volume of the slab is first enlarged by $20 \%$, and melted at a high temperature of $6000 \mathrm{~K}$ for 100000 steps so that a disordered state is reached. The volume is then scaled down to its original value, and the system is equilibrated at $6000 \mathrm{~K}$ for another 100000 steps. In the third step, the temperature of system is quickly cooled down to $400 \mathrm{~K}$, the average temperature for NEMD simulations. ${ }^{23}$ Finally, the system is equilibrated at $400 \mathrm{~K}$ in canonical ensemble (NVT) for 100000 steps followed by an equilibration of 100000 steps in microcanonical ensemble (NVE). The initial structure of the amorphous few-layer structure is formed by assembling the amorphous slabs of each material in the $z$ direction. Before applying the temperature difference for the NEMD simulation, the initial amorphous few-layer structure is optimized and equilibrated first in isothermal-isobaric ensemble (NPT), then NVT and finally NVE.

\section{A. Non-equilibrium molecular dynamics simulations}

MD simulations are performed using the Large-Scale Atomic/ Molecular Massively Parallel Simulator (LAMMPS). ${ }^{\mathbf{2 4 2 5}}$ The schematic of the $\mathrm{SiO}_{2} / \mathrm{Al}_{2} \mathrm{O}_{3}$ multilayer structures is shown in Fig. 1. In the NEMD simulations, periodic boundary conditions are applied in the $x$ and $y$ directions while the two ends in the $z$ direction are set free. A time step of $1 \mathrm{fs}$ is used in all MD simulations. In order to reduce the stress, the initial structure is optimized and equilibrated in the NPT. Then NVT and NVE simulations are carried out to obtain the initial structure at specified temperature. The NEMD simulations are performed under NVE with specified temperature difference.

As shown in Fig. 1, a heating bath and a cooling bath are applied at left end and right end of the system, respectively. The

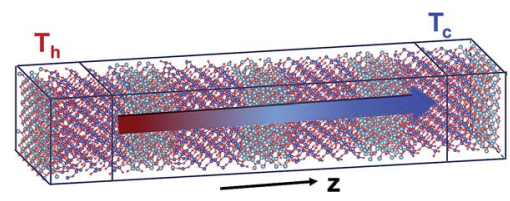

Fig. 1 Schematic of lattice structures in NEMD simulations. 
heating/cooling bath is $3 \mathrm{~nm}$ long with $\sim 2000$ atoms. The constant temperatures at $410 \mathrm{~K}$ and $390 \mathrm{~K}$ are maintained by rescaling the velocities of atoms in the heating and cooling baths, respectively. ${ }^{26}$ In order to reach the steady state, we first perform NEMD simulations for $10 \mathrm{~ns}$ before sampling. Then we sample the temperature along the $z$ direction for another $20 \mathrm{~ns}$. According to Fourier's law, the thermal conductivity is calculated as $k=\dot{q} /(A \mathrm{~d} T / \mathrm{d} x)$, where $\dot{q}, A$ and $\mathrm{d} T / \mathrm{d} x$ are the heat transfer rate, the cross-section area and the temperature gradient in heat flux direction, respectively. The linear fitting of the cumulative energy change and the temperature profiles are performed to determine the heat transfer rate and temperature gradient, respectively.

\section{B. Phonon dispersion and participation ratio}

In dielectric materials, phonons are the energy carriers responsible for the heat conduction. In order to gain more insights of the mechanism of the thermal transport in multilayer dielectrics, we calculate the phonon dispersions, group velocities, and participation ratio. Based on the BKS potential and lattice structures above mentioned, the vibrational eigen-modes are obtained from the lattice dynamics using the general utility lattice program (GULP). ${ }^{27}$ The phonon group velocities are calculated from the phonon dispersion relations using central difference scheme, $v(s, q)=\partial \omega_{\mathrm{s}} / \partial q$, where $s$ and $q$ are the indices of phonon polarization and wave vector, respectively.

The phonon participation ratio is used to quantitatively characterize the localization of each mode, which can be calculated from the following formulism. ${ }^{28}$

$$
P(s, q)=\frac{\left(\sum_{i} \vec{e}_{s, q}{ }^{2}\right)^{2}}{N \sum_{i} \vec{e}_{s, q}^{4}}
$$

where $\vec{e}_{s, q}$ is the eigenvector of mode $(s, q)$, and $i$ runs over all the $N$ atoms in the system. According to this definition, the participation ratio is on the order of 1 for the spatially extended modes while it can be as small as $1 / N$ for the completely localized mode.

\section{Results and discussion}

\section{A. Thermal resistance analysis of multilayer structures}

The thermal conductivities of both the crystalline and amorphous $\mathrm{SiO}_{2}$ and $\mathrm{Al}_{2} \mathrm{O}_{3}$ are calculated using NEMD simulations. ${ }^{23}$ The thickness dependence of thermal conductivity of crystalline $\mathrm{SiO}_{2}$ and $\mathrm{Al}_{2} \mathrm{O}_{3}$ is shown in Fig. 2. It can be observed that both the thermal conductivities of crystalline $\mathrm{SiO}_{2}$ and $\mathrm{Al}_{2} \mathrm{O}_{3}$ increases as the thickness increases which indicates the mean free path longer than the simulation domain is limited. A linear relation between $1 / k$ and $1 / L$ can be observed as shown in Fig. $2(b)$, and it is consistent with the Matthiessen's rule as described by Schelling et al. ${ }^{29}$ The relation is linearly extrapolated to $L \rightarrow \infty$, yielding thermal conductivities of $7.0 \mathrm{~W}\left(\mathrm{~m}^{-1} \mathrm{~K}^{-1}\right)$ and $7.9 \mathrm{~W}$ $\left(\mathrm{m}^{-1} \mathrm{~K}^{-1}\right)$ for bulk crystalline $\mathrm{SiO}_{2}$ and $\mathrm{Al}_{2} \mathrm{O}_{3}$, respectively. Based on NEMD simulations, the thermal conductivities of amorphous $\mathrm{SiO}_{2}$ and $\mathrm{Al}_{2} \mathrm{O}_{3}$ are $1.7 \mathrm{~W}\left(\mathrm{~m}^{-1} \mathrm{~K}^{-1}\right)$ and $2.2 \mathrm{~W}\left(\mathrm{~m}^{-1} \mathrm{~K}^{-1}\right)$,
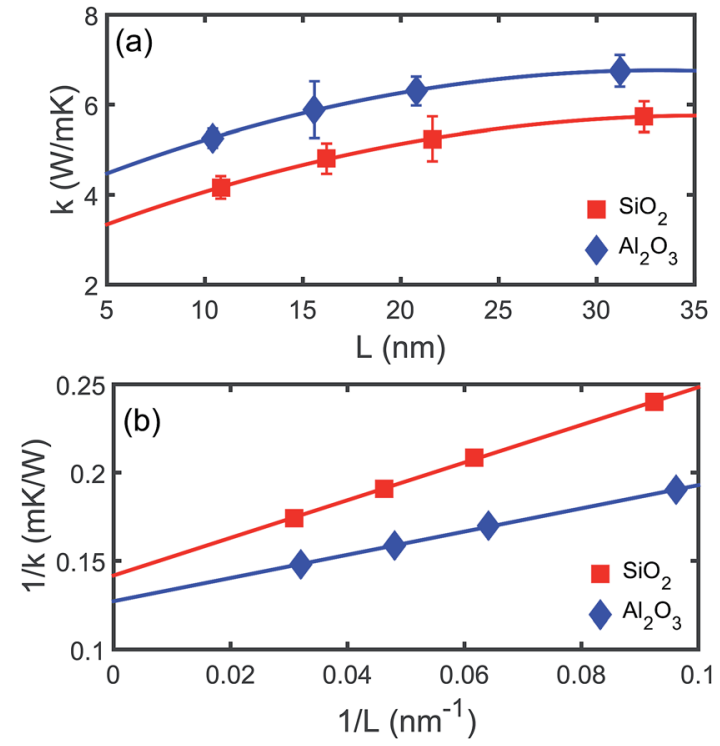

Fig. 2 Thermal conductivity of (a) crystalline $\mathrm{SiO}_{2}$ and (b) crystalline $\mathrm{Al}_{2} \mathrm{O}_{3}$ films as a function of thickness.

respectively. The predictions are comparable with the experimental results in literatures, e.g. $1.0-1.5 \mathrm{~W}\left(\mathrm{~m}^{-1} \mathrm{~K}^{-1}\right)$ for $\mathrm{SiO}_{2}$ (ref. 30-32) and $1.8-2.8 \mathrm{~W}\left(\mathrm{~m}^{-1} \mathrm{~K}^{-1}\right),{ }^{33}$ and the deviations may be due to the difference in density and the error from the empirical potential model. The thickness dependence is not observed for the amorphous $\mathrm{SiO}_{2}$ or $\mathrm{Al}_{2} \mathrm{O}_{3}$ due to the small phonon mean free path in the amorphous structures.

The TBR between crystalline $\mathrm{SiO}_{2}$ and $\mathrm{Al}_{2} \mathrm{O}_{3}$ is calculated from NEMD simulations at two interfaces of different bonding as illustrated by the insets of Fig. 3. The $\mathrm{Al}_{2} \mathrm{O}_{3} / \mathrm{SiO}_{2}$ interface
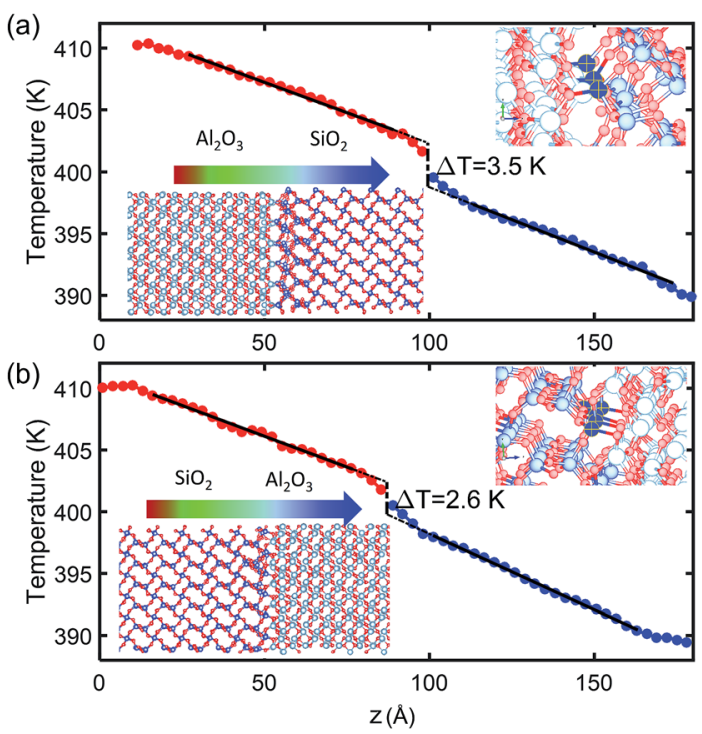

Fig. 3 Temperature profiles at interfaces between crystalline $\mathrm{SiO}_{2}$ and $\mathrm{Al}_{2} \mathrm{O}_{3}$ of different bonding: (a) $\mathrm{Al}_{2} \mathrm{O}_{3} / \mathrm{SiO}_{2}$ interface with poor contact; (b) $\mathrm{SiO}_{2} / \mathrm{Al}_{2} \mathrm{O}_{3}$ interface with good contact. The solid lines indicate the linear fitting while the dashed lines are the extrapolations. The upper right insets show the zoom-in of the $\mathrm{Si}$ bonded with $\mathrm{O}$ in $\mathrm{Al}_{2} \mathrm{O}_{3}$ at the interfaces. 
shown in Fig. 3(a) has $\mathrm{Al}$ and $\mathrm{Si}$ atoms aligned at the same $x-z$ plane, and fewer $\mathrm{O}$ atoms are available to form $\mathrm{Si}-\mathrm{O}$ and $\mathrm{Al}-\mathrm{O}$ bonds at the interface. The $\mathrm{SiO}_{2} / \mathrm{Al}_{2} \mathrm{O}_{3}$ interface shown in Fig. 3(b) has $\mathrm{Al}$ and $\mathrm{Si}$ atoms staggered, and more $\mathrm{O}$ atoms can be found at the interface to form a good contact with increased $\mathrm{Si}-\mathrm{O}$ and $\mathrm{Al}-\mathrm{O}$ bonds. A zoom-in of the bonding at interface are shown in Fig. 3 which can clearly shows the difference of $\mathrm{Si}-\mathrm{O}$ at interfaces of the two structures. In both structures, there are totally $30 \mathrm{Al}$ atoms at interface all of which form bonds with $\mathrm{O}$ atoms in $\mathrm{SiO}_{2}$. In the $\mathrm{Al}_{2} \mathrm{O}_{3} / \mathrm{SiO}_{2}$ interface with poor contact, around $16 \mathrm{Si}$ atoms can form bonds with $\mathrm{O}$ in $\mathrm{Al}_{2} \mathrm{O}_{3}$. In $\mathrm{SiO}_{2}$ / $\mathrm{Al}_{2} \mathrm{O}_{3}$ interface with good contact, all the $30 \mathrm{Si}$ atoms can form bonds with $\mathrm{Al}_{2} \mathrm{O}_{3}$. As a result, the bond densities across the interfaces are 7.8 per $\mathrm{nm}^{2}$ and 10.2 per $\mathrm{nm}^{2}$. According to the temperature profiles along the direction of heat conduction shown in Fig. 3, the linear temperature profiles in $\mathrm{SiO}_{2}$ and $\mathrm{Al}_{2} \mathrm{O}_{3}$ are extrapolated to the interface. Interfacial temperature differences of $3.5 \mathrm{~K}$ and $2.6 \mathrm{~K}$ are obtained for the two interfaces. The corresponding TBRs $\left(R_{1}\right.$ and $\left.R_{2}\right)$ at $400 \mathrm{~K}$ are $0.67 \mathrm{~m}^{2}$ $\mathrm{K} \mathrm{GW}^{-1}$ and $0.41 \mathrm{~m}^{2} \mathrm{~K} \mathrm{GW}^{-1}$, respectively. It can also been observed that the temperature gradient within $\mathrm{SiO}_{2}$ and $\mathrm{Al}_{2} \mathrm{O}_{3}$ becomes larger near the interface, contributing to the interfacial temperature difference. This is because the phonon scattering is increased by the tangling of lattices near the interface.

If the phonon transport through each film is fully ballistic, the film resistances become negligible and the TBRs dominate the thermal conductivity of multilayer structures. The effective thermal conductivity $k_{\text {eff }}$ can be determined according to the thermal resistance analysis, $\left(t_{\mathrm{SiO}_{2}}+t_{\mathrm{Al}_{2} \mathrm{O}_{3}}\right) / k_{\text {eff }}=R_{1}+R_{2}$, where $t$ and $R$ denotes the thickness and the thermal boundary resistance, respectively. The effective thermal conductivities are $6.2 \mathrm{~W}\left(\mathrm{~m}^{-1} \mathrm{~K}^{-1}\right)$ and $3.0 \mathrm{~W}\left(\mathrm{~m}^{-1} \mathrm{~K}^{-1}\right)$ for $4 \mathrm{~nm}-\mathrm{SiO}_{2} / 2 \mathrm{~nm}-\mathrm{Al}_{2} \mathrm{O}_{3}$ and $2 \mathrm{~nm}-\mathrm{SiO}_{2} / 1 \mathrm{~nm}-\mathrm{Al}_{2} \mathrm{O}_{3}$ multilayer structures, respectively. Including the thermal resistance of alternating films, the effective thermal conductivity of $\mathrm{SiO}_{2} / \mathrm{Al}_{2} \mathrm{O}_{3}$ multilayer structures can be estimated from the resistance analysis, e.g. $\left(t_{\mathrm{SiO}_{2}}+\right.$ $\left.t_{\mathrm{Al}_{2} \mathrm{O}_{3}}\right) / k_{\text {eff }}=(t / k)_{\mathrm{SiO}_{2}}+(t / k)_{\mathrm{Al}_{2} \mathrm{O}_{3}}+R_{1}+R_{2}$. The effective thermal conductivities are $3.4 \mathrm{~W}\left(\mathrm{~m}^{-1} \mathrm{~K}^{-1}\right)$ and $2.1 \mathrm{~W}\left(\mathrm{~m}^{-1} \mathrm{~K}^{-1}\right)$ for 4 $\mathrm{nm}-\mathrm{SiO}_{2} / 2 \mathrm{~nm}-\mathrm{Al}_{2} \mathrm{O}_{3}$ and $2 \mathrm{~nm}-\mathrm{SiO}_{2} / 1 \mathrm{~nm}-\mathrm{Al}_{2} \mathrm{O}_{3}$ multilayer structures, respectively. Since the bulk thermal conductivity is used for films of different thickness, the film-thickness dependence of the effective thermal conductivities of multilayer structures is caused by the interface density. The comparison of different resistance terms indicates the TBR contributes about $54 \%$ and $71 \%$ for the two multilayer structures. Considering the decrease of thermal conductivity of thin films, the film thermal resistance will increase, leading to further reduction of the effective thermal conductivity of the crystalline multilayer structures. However, the NEMD simulations on the amorphous structures show negligible temperature difference at interface between amorphous $\mathrm{SiO}_{2}$ and $\mathrm{Al}_{2} \mathrm{O}_{3}$, which indicates negligible TBR. The amorphous structure enhance the contact, and more bonding can be formed via the $\mathrm{O}$ atoms between $\mathrm{SiO}_{2}$ and $\mathrm{Al}_{2} \mathrm{O}_{3}$. The other reason for the negligible TBR is that the phonon mean free path inside the films are very small and are not affected by the interface.

\section{B. Direct NEMD simulations of multilayer structures}

Fig. 4 shows the temperature profile across the crystalline $\mathrm{SiO}_{2} /$ $\mathrm{Al}_{2} \mathrm{O}_{3}$ multilayer structures with total thickness of $26.5 \mathrm{~nm}$. The lower insets under the temperature profiles indicate the alternating $\mathrm{SiO}_{2}$ and $\mathrm{Al}_{2} \mathrm{O}_{3}$ layers and the location of their interfaces. In both $2 \mathrm{~nm}-\mathrm{SiO}_{2} / 1 \mathrm{~nm}-\mathrm{Al}_{2} \mathrm{O}_{3}$ and $4 \mathrm{~nm}-\mathrm{SiO}_{2} / 2 \mathrm{~nm}-\mathrm{Al}_{2} \mathrm{O}_{3}$ multilayer structures, it can be observed that a noticeable temperature drop repeatedly occurs at the $\mathrm{SiO}_{2} / \mathrm{Al}_{2} \mathrm{O}_{3}$ interfaces that are marked in the lower inset. As shown in Fig. 4(a), the last temperature drop near the cooling bath end is indicated by the circle with an arrow pointing to the zoom-in of the interface atomic structures. According to the discussion in Section 3A, this interface structure has fewer bond connections, leading to a relatively large TBR as well as temperature drop, which is similar with the one as shown in Fig. 3.

The temperature profiles in Fig. 4(a) also indicate that temperature variations are quite small within the $2 \mathrm{~nm} \mathrm{SiO}_{2}$ films and $1 \mathrm{~nm} \mathrm{Al}_{2} \mathrm{O}_{3}$ films. So the thermal transport in the 2 $\mathrm{nm}-\mathrm{SiO}_{2} / 1 \mathrm{~nm}-\mathrm{Al}_{2} \mathrm{O}_{3}$ multilayer structures is dominated by the interface phonon scattering while the phonon transport across the films is nearly ballistic. As the film thickness is increased, as in Fig. 4(b), the temperature variations $(\sim 2.5 \mathrm{~K})$ within the films has exceeded the temperature differences $(\sim 3.5 \mathrm{~K})$ at the interfaces. As a result, both the interfacial phonon scattering and the internal phonon-phonon scattering are important in determining the thermal conductivity of crystalline $\mathrm{SiO}_{2} / \mathrm{Al}_{2} \mathrm{O}_{3}$ multilayer structures with thicker layers. For all the amorphous $\mathrm{SiO}_{2} / \mathrm{Al}_{2} \mathrm{O}_{3}$ multilayer structures in the present work, the temperature drop at $\mathrm{SiO}_{2}$ and $\mathrm{Al}_{2} \mathrm{O}_{3}$ interface is not observed, and the temperature profile is linear and smoother except for the region near the heat baths. This observation is in agreement with the above results of the NEMD simulations $\mathrm{SiO}_{2} / \mathrm{Al}_{2} \mathrm{O}_{3}$ interface. Therefore, the thermal conductivity of amorphous
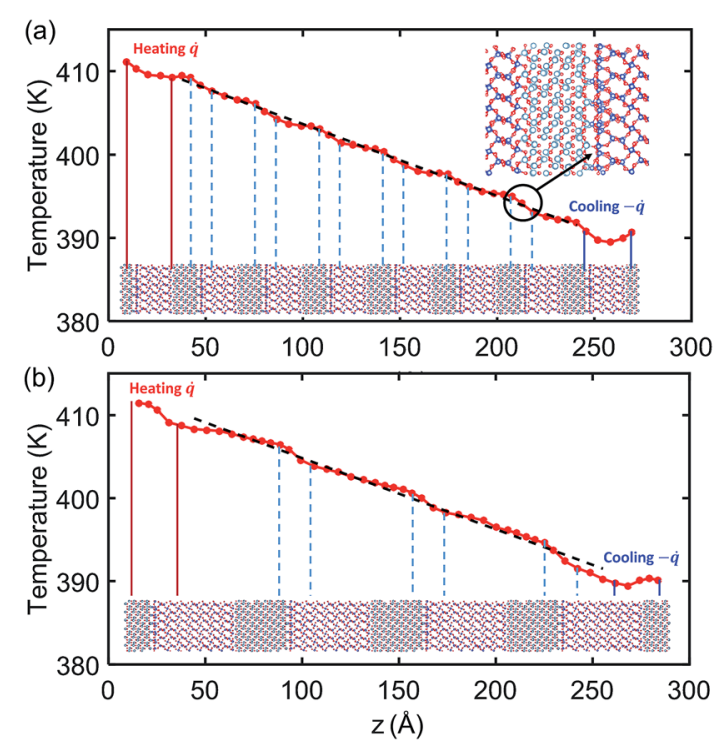

Fig. 4 Temperature profiles across (a) $2 \mathrm{~nm}-\mathrm{SiO}_{2} / 1 \mathrm{~nm}-\mathrm{Al}_{2} \mathrm{O}_{3}$ crystalline multilayer structures and (b) $4 \mathrm{~nm}-\mathrm{SiO}_{2} / 2 \mathrm{~nm}-\mathrm{Al}_{2} \mathrm{O}_{3}$ crystalline multilayer structures. The dashed line is the linear fitting. 
$\mathrm{SiO}_{2} / \mathrm{Al}_{2} \mathrm{O}_{3}$ multilayer structures should only depend on the internal phonon-phonon scattering.

The thermal conductivity of the multilayer structures is calculated using the temperature gradient from the linear fitting of the temperature profiles as shown in Fig. 4. The NEMD simulations are performed on both $2 \mathrm{~nm}-\mathrm{SiO}_{2} / 1 \mathrm{~nm}-\mathrm{Al}_{2} \mathrm{O}_{3}$ and 4 $\mathrm{nm}-\mathrm{SiO}_{2} / 2 \mathrm{~nm}-\mathrm{Al}_{2} \mathrm{O}_{3}$ multilayer structures with total thicknesses ranging from $13.6 \mathrm{~nm}$ to $68.2 \mathrm{~nm}$. The predictions of the effective thermal conductivity are shown in Fig. 5 . The thermal conductivity of $4 \mathrm{~nm}-\mathrm{SiO}_{2} / 2 \mathrm{~nm}-\mathrm{Al}_{2} \mathrm{O}_{3}$ multilayer structures shows size dependence when the total thickness is below $40 \mathrm{~nm}$. The size dependence indicates the contribution of phonon-phonon scattering is non-negligible. In multilayer structures consisting of thick slabs, phonons can have relatively large mean free path and transmit across interfaces. Those phonons are finally scattered at boundaries due to the small domain size, and the increase of the domain size can allow the presence of phonons with longer mean free path as well as increasing the thermal conductivity. However, in multilayer structures consisting of thin slabs, the interface scattering is so intense that the thermal conductivity is determined mainly by the TBR at interfaces and does not show any dependence on the domain size.

As shown in Fig. 5, the thick $4 \mathrm{~nm}-\mathrm{SiO}_{2} / 2 \mathrm{~nm}-\mathrm{Al}_{2} \mathrm{O}_{3}$ multilayer structure has thermal conductivity approaching $3.0 \mathrm{~W}$ $\left(\mathrm{m}^{-1} \mathrm{~K}^{-1}\right)$ which is about $50 \%$ higher than that $\left(\sim 2.1 \mathrm{~W}\left(\mathrm{~m}^{-1}\right.\right.$ $\left.\mathrm{K}^{-1}\right)$ ) of the $2 \mathrm{~nm}-\mathrm{SiO}_{2} / 1 \mathrm{~nm}-\mathrm{Al}_{2} \mathrm{O}_{3}$ multilayer structure. Both the predictions of the two multilayer structures by the direct NEMD simulations agree with the results of above thermal resistance analysis (Section 3A) which incorporates both the film resistances and TBRs. For the $4 \mathrm{~nm}-\mathrm{SiO}_{2} / 2 \mathrm{~nm}-\mathrm{Al}_{2} \mathrm{O}_{3}$ multilayer structure, the direct NEMD prediction is slightly lower than the prediction $\left(3.4 \mathrm{~W}\left(\mathrm{~m}^{-1} \mathrm{~K}^{-1}\right)\right.$ ) of the above thermal resistance analysis (Section 3A). This can be because the use of the bulk thermal conductivity which is expected to be higher than that of the thin films. However, the TBR resistances can account for $71 \%$ of the total resistance for the $2 \mathrm{~nm}-\mathrm{SiO}_{2} / 1 \mathrm{~nm}-\mathrm{Al}_{2} \mathrm{O}_{3}$ multilayer structure. So the variations of thermal resistance of thin films have little effect on its effective thermal conductivity,

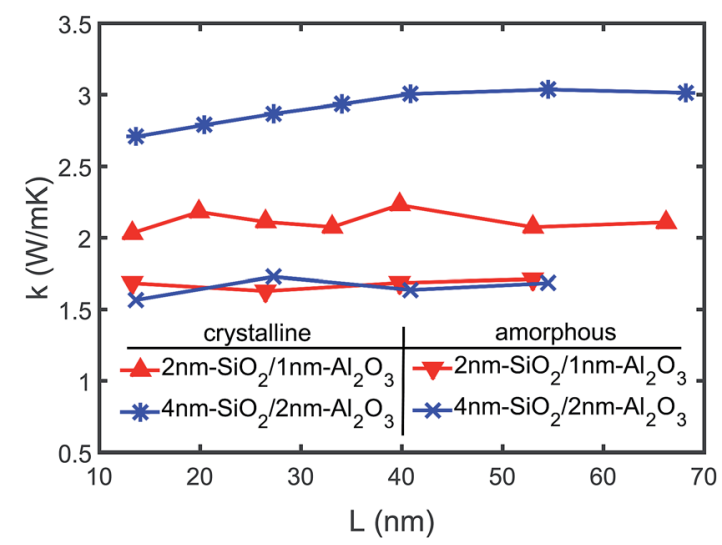

Fig. 5 Thermal conductivity of $\mathrm{SiO}_{2} / \mathrm{Al}_{2} \mathrm{O}_{3}$ multilayer structures as a function of thickness. and the predictions by the direct NEMD simulations match well with the results $\left(2.1 \mathrm{~W}\left(\mathrm{~m}^{-1} \mathrm{~K}^{-1}\right)\right)$ of thermal resistance analysis for $2 \mathrm{~nm}-\mathrm{SiO}_{2} / 1 \mathrm{~nm}-\mathrm{Al}_{2} \mathrm{O}_{3}$ multilayer structures.

Fig. 5 also shows the variations of the effective thermal conductivity of amorphous $\mathrm{SiO}_{2} / \mathrm{Al}_{2} \mathrm{O}_{3}$ multilayer structures with difference film thickness and total thickness. It can be observed that neither the film thickness nor the total thickness has any effect on the thermal conductivity of amorphous $\mathrm{SiO}_{2}$ / $\mathrm{Al}_{2} \mathrm{O}_{3}$ multilayer structures. The mean value of the predictions shown in Fig. 5 is $1.7 \mathrm{~W}\left(\mathrm{~m}^{-1} \mathrm{~K}^{-1}\right)$ which is same with the thermal conductivity of amorphous $\mathrm{SiO}_{2}$ but smaller than the amorphous $\mathrm{Al}_{2} \mathrm{O}_{3}$. Since the TBR between amorphous $\mathrm{SiO}_{2}$ and $\mathrm{Al}_{2} \mathrm{O}_{3}$ is negligible, the thermal conductivity of the amorphous $\mathrm{Al}_{2} \mathrm{O}_{3}$ films is lowered in amorphous $\mathrm{SiO}_{2} / \mathrm{Al}_{2} \mathrm{O}_{3}$ multilayer structures. It should be noted that this observation is only valid for the nanometer thick films. As the film thickness increases to tens of nanometer, the effects of $\mathrm{SiO}_{2}$ on the thermal conductivity of amorphous $\mathrm{Al}_{2} \mathrm{O}_{3}$ film will diminish.

\section{Vibrational mode analysis}

The phonon eigen vectors and frequencies are obtained from lattice dynamics calculations using GULP. The unit cells are used for bulk crystalline $\mathrm{SiO}_{2}$ and $\mathrm{Al}_{2} \mathrm{O}_{3}$, while one $\mathrm{SiO}_{2} / \mathrm{Al}_{2} \mathrm{O}_{3}$ slab with cross-sectional area of $2.5 \mathrm{~nm} \times 2.5 \mathrm{~nm}$ and different layer thicknesses is used as the cell of both the crystalline and the amorphous multilayer structures. Fig. 6 shows the acoustic branches of phonon dispersion curves and group velocities of bulk $\mathrm{SiO}_{2}$, bulk $\mathrm{Al}_{2} \mathrm{O}_{3}, 4 \mathrm{~nm}-\mathrm{SiO}_{2} / 2 \mathrm{~nm}-\mathrm{Al}_{2} \mathrm{O}_{3}$ slab, and $2 \mathrm{~nm}$ $\mathrm{SiO}_{2} / 1 \mathrm{~nm}-\mathrm{Al}_{2} \mathrm{O}_{3}$ slab. The maximum group velocities of phonons (longitudinal) in bulk $\mathrm{SiO}_{2}$ and bulk $\mathrm{Al}_{2} \mathrm{O}_{3}$, are around $9 \mathrm{~km} \mathrm{~s}^{-1}$ and $11 \mathrm{~km} \mathrm{~s}^{-1}$, respectively. Compared with the bulk materials, the group velocities of the longitudinal phonons in 4 $\mathrm{nm}-\mathrm{SiO}_{2} / 2 \mathrm{~nm}-\mathrm{Al}_{2} \mathrm{O}_{3}$ slab and $2 \mathrm{~nm}-\mathrm{SiO}_{2} / 1 \mathrm{~nm}-\mathrm{Al}_{2} \mathrm{O}_{3}$ slab are reduced to $7.5 \mathrm{~km} \mathrm{~s}^{-1}$ and $6.5 \mathrm{~km} \mathrm{~s}^{-1}$, respectively. The group velocities of the transverse acoustics phonons remain similar with those in the bulk materials. In the multilayer structures, the presence of $\mathrm{SiO}_{2} / \mathrm{Al}_{2} \mathrm{O}_{3}$ interfaces increases the boundary scattering of the longitudinal phonons which propagate in the direction perpendicular to the interface rather than the transverse phonons. Acoustic phonons with high group velocity and long mean free path are responsible for the thermal transport. The increased scattering of longitudinal phonon modes leads to the reduction of the thermal conductivity of multilayer structures.

The lattice tangling and deformation near the interfaces can also increase the phonon scattering. Mode localization of phonons is believed to be responsible for the reduction of thermal conductivity in materials with lattice defects or disorder systems. ${ }^{34}$ The phonon participation ratio quantitatively characterizes the mode localization of phonons. In order to represent the spatial variations of mode location near the $\mathrm{SiO}_{2} / \mathrm{Al}_{2} \mathrm{O}_{3}$ interfaces, the structures are split into bins with a width of $3 \AA$, and the phonon participation ratio is calculated for atoms in each bin.

Fig. 7 shows the partition ratio of phonons as a function of location for crystalline $\mathrm{SiO}_{2} / \mathrm{Al}_{2} \mathrm{O}_{3}$ interface, crystalline $4 \mathrm{~nm}$ - 


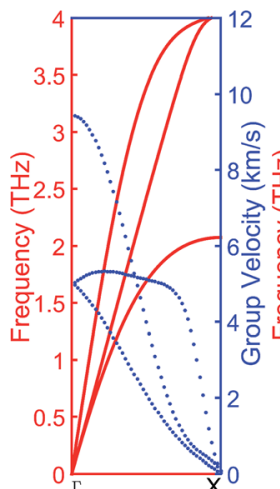

(a) $\mathrm{SiO}_{2}$

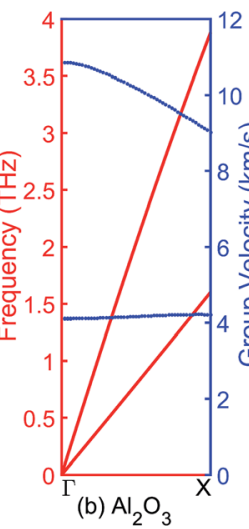

(b) $\mathrm{Al}_{2} \mathrm{O}_{3}$

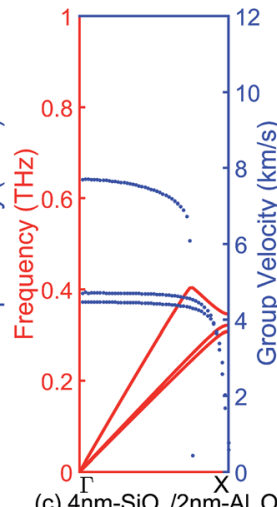

(c) $4 \mathrm{~nm}-\mathrm{SiO}_{2} / 2 \mathrm{~nm}-\mathrm{Al}_{2} \mathrm{O}_{3}$

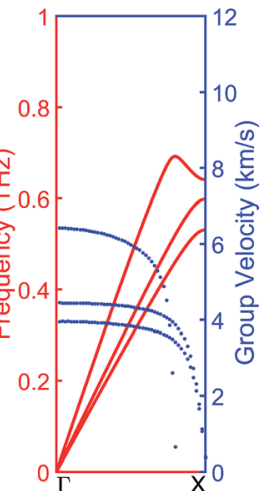

(d) $2 \mathrm{~nm}-\mathrm{SiO}_{2} / 1 \mathrm{~nm}-\mathrm{Al}_{2} \mathrm{O}_{3}$

Fig. 6 Acoustic branches of phonon dispersion curves and group velocities of (a) $\mathrm{SiO}_{2}$, (b) $\mathrm{Al}_{2} \mathrm{O}_{3}$, (c) $4 \mathrm{~nm}-\mathrm{SiO}_{2} / 2 \mathrm{~nm}-\mathrm{Al}_{2} \mathrm{O}_{3}$ multilayer structures, and (d) $2 \mathrm{~nm}-\mathrm{SiO}_{2} / 1 \mathrm{~nm}-\mathrm{Al}_{2} \mathrm{O}_{3}$ multilayer structures.
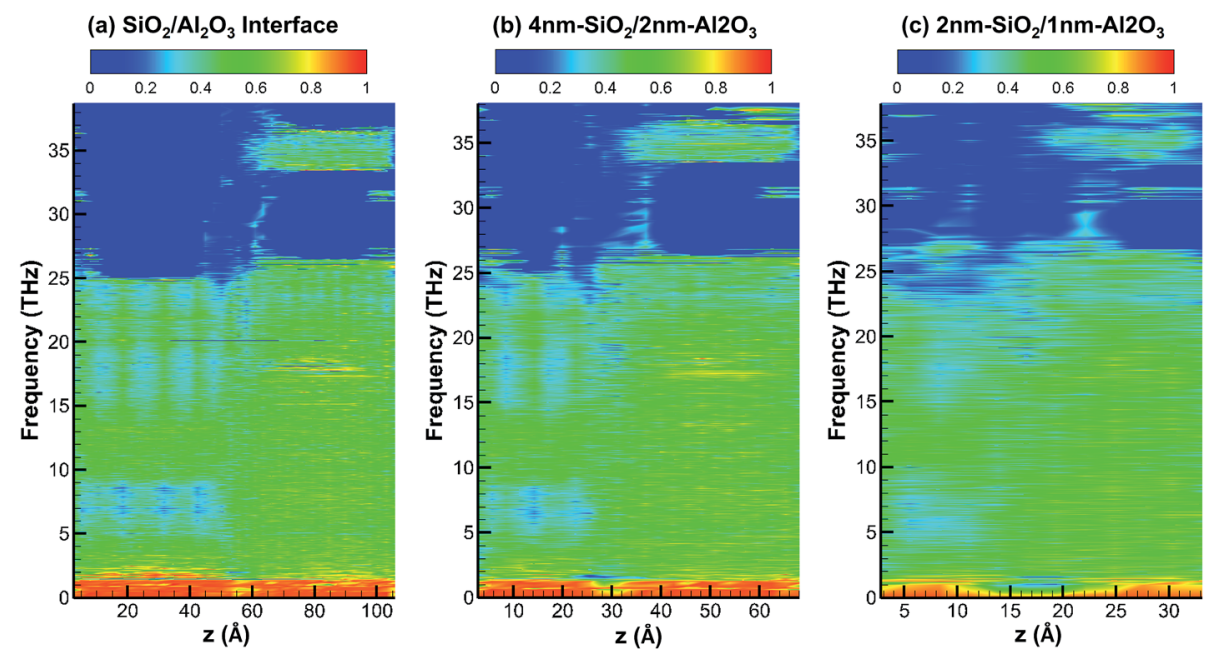

Fig. 7 Partition ratio of phonons as a function of location for crystalline $\mathrm{SiO}_{2} / \mathrm{Al}_{2} \mathrm{O}_{3}$ interface, $4 \mathrm{~nm}-\mathrm{SiO}_{2} / 2 \mathrm{~nm}-\mathrm{Al}_{2} \mathrm{O}_{3} \mathrm{crystalline}$ structures, and $2 \mathrm{~nm}-\mathrm{SiO}_{2} / 1 \mathrm{~nm}-\mathrm{Al}_{2} \mathrm{O}_{3}$ crystalline structures.

$\mathrm{SiO}_{2} / 2 \mathrm{~nm}-\mathrm{Al}_{2} \mathrm{O}_{3}$ slab, and crystalline $2 \mathrm{~nm}-\mathrm{SiO}_{2} / 1 \mathrm{~nm}-\mathrm{Al}_{2} \mathrm{O}_{3}$ slab. For all the three systems, the phonons are partially localized with PR around 0.5 in the frequency range from $2 \mathrm{THz}$ to 25 THz. Above $25 \mathrm{THz}$, the PR only show some partially localized modes in $\mathrm{SiO}_{2}$ from $32 \mathrm{THz}$ to $40 \mathrm{THz}$. It can be observed that the acoustic phonons with frequency below $2 \mathrm{THz}$ mainly consists of delocalized modes with PR around 1 in the first two systems of $\mathrm{SiO}_{2} / \mathrm{Al}_{2} \mathrm{O}_{3}$ interface and $4 \mathrm{~nm}-\mathrm{SiO}_{2} / 2 \mathrm{~nm}-\mathrm{Al}_{2} \mathrm{O}_{3}$ slab. However, in the $2 \mathrm{~nm}-\mathrm{SiO}_{2} / 1 \mathrm{~nm}-\mathrm{Al}_{2} \mathrm{O}_{3}$ slab, the portion of modes with high PR diminishes indicating those phonon modes become partially localized. Around the $\mathrm{SiO}_{2} / \mathrm{Al}_{2} \mathrm{O}_{3}$ interface in the $2 \mathrm{~nm}-\mathrm{SiO}_{2} / 1 \mathrm{~nm}-\mathrm{Al}_{2} \mathrm{O}_{3}$ slab, the PR is nearly zero which indicates the mode localization near the interfaces. With the decrease of film thickness, the lattice deformation can extend to the entire film, intensify the phonon scattering and mode localization, and lead to the decrease of thermal conductivity of multilayer structures.

Fig. 8 shows the partition ratio of phonons as a function of location for amorphous $4 \mathrm{~nm}-\mathrm{SiO}_{2} / 2 \mathrm{~nm}-\mathrm{Al}_{2} \mathrm{O}_{3}$ slab, and amorphous $2 \mathrm{~nm}-\mathrm{SiO}_{2} / 1 \mathrm{~nm}-\mathrm{Al}_{2} \mathrm{O}_{3}$ slab. It can be observed that (a) $4 \mathrm{~nm}-\mathrm{SiO}_{2} / 2 \mathrm{~nm}-\mathrm{Al}_{2} \mathrm{O}_{3}$
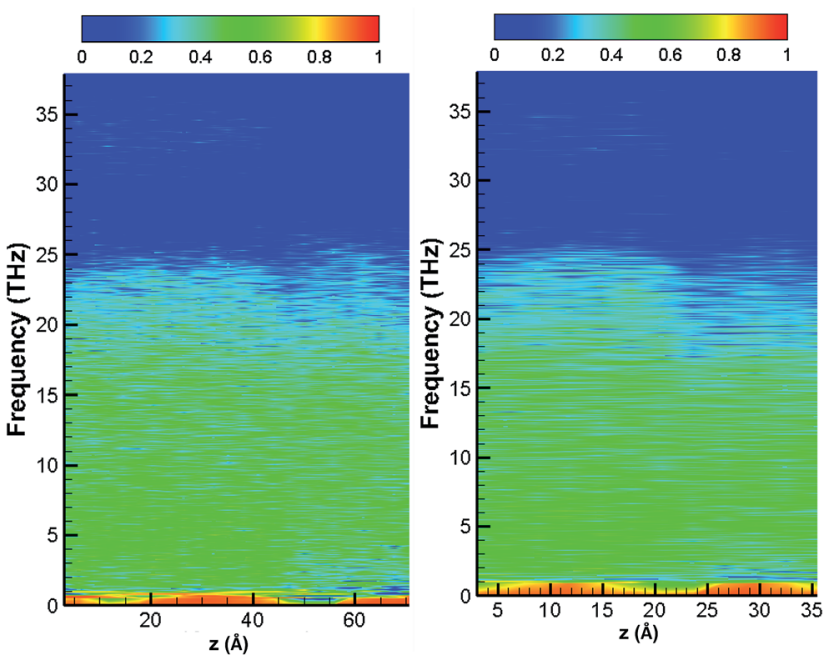

Fig. 8 Partition ratio of phonons as a function of location for $4 \mathrm{~nm}$ $\mathrm{SiO}_{2} / 2 \mathrm{~nm}-\mathrm{Al}_{2} \mathrm{O}_{3}$ amorphous structures and $2 \mathrm{~nm}-\mathrm{SiO}_{2} / 1 \mathrm{~nm}-\mathrm{Al}_{2} \mathrm{O}_{3}$ amorphous structures. 
there is little difference of PR distribution between the two amorphous structures. As compared with the PR distribution of crystalline structures as shown in Fig. 7, the PR becomes smaller for the amorphous structures, especially for the region above $20 \mathrm{THz}$ for both $\mathrm{SiO}_{2}$ and $\mathrm{Al}_{2} \mathrm{O}_{3}$. The observations from Fig. 8 indicate presence of $\mathrm{SiO}_{2}$ film leads to the localization of phonons in $\mathrm{Al}_{2} \mathrm{O}_{3}$ as well as the reduction of its thermal conductivity. Therefore, the amorphous $\mathrm{SiO}_{2}$ and $\mathrm{Al}_{2} \mathrm{O}_{3}$ structures exhibit thermal conductivity same with amorphous $\mathrm{SiO}_{2}$ regardless of the slightly higher thermal conductivity of amorphous $\mathrm{Al}_{2} \mathrm{O}_{3}$.

\section{Conclusions}

In summary, we have studied the thermal transport in both the crystalline and amorphous $\mathrm{SiO}_{2} / \mathrm{Al}_{2} \mathrm{O}_{3}$ multilayer structures using NEMD simulations and lattice dynamics calculations. The NEMD predictions of thermal conductivity are compared with the results of thermal resistance analysis. The results suggest both the TBR and film resistance are important for calculating the thermal conductivity of crystalline multilayer dielectric structures. The film resistance arising from internal phonon-phonon scattering becomes equally important as TBR in crystalline $\mathrm{SiO}_{2}$ films of thickness around $4 \mathrm{~nm}$. The thermal conductivity of amorphous $\mathrm{SiO}_{2}$ and $\mathrm{Al}_{2} \mathrm{O}_{3}$ structures shows no dependence on the film thickness or total thickness. Based on the lattice dynamics calculations and localization mode analysis, we find the phonon localization is responsible for the decrease of thermal conductivity of crystalline multilayer structures, especially in structures consisting of very thin films. Our study is expected to be valuable for the thermal insulation design of PCM devices and to provide insights for understanding the mechanism of thermal transport of multilayer structures of few-nanometer-thick dielectric films.

\section{Acknowledgements}

This work was supported by the China Postdoctoral Science Foundation (2015M580844), the Fundamental Research Funds for the Central Universities (2012JDGZ03), and the Natural Science Foundation of Jiangsu Province (BK20160388).

\section{References}

1 F. Dirisaglik, G. Bakan, Z. Jurado, S. Muneer, M. Akbulut, J. Rarey, L. Sullivan, M. Wennberg, A. King and L. Zhang, Nanoscale, 2015, 7, 16625-16630.

2 K. H. Kim, S. Gaba, D. Wheeler, J. M. Cruz-Albrecht, T. Hussain, N. Srinivasa and W. Lu, Nano Lett., 2012, 12, 389-395.

3 R. E. Simpson, M. Krbal, P. Fons, A. V. Kolobov, J. Tominaga, T. Uruga and H. Tanida, Nano Lett., 2010, 10, 414-419.

4 Y. Cassuto, S. Kvatinsky and E. Yaakobi, 2013 IEEE International Symposium on Information Theory Proceedings, 2013, pp. 156-160.
5 M. Upadhyay, S. Abhaya, S. Murugavel and G. Amarendra, RSC Adv., 2014, 4, 3691.

6 D. Ielmini and A. L. Lacaita, Mater. Today, 2011, 14, 600-607.

7 Z. J. Li, R. G. D. Jeyasingh, J. Lee, M. Asheghi, H. S. P. Wong and K. E. Goodson, IEEE Trans. Electron Devices, 2012, 59, 3561-3567.

8 A. Sood, S. B. Eryilmaz, R. Jeyasingh, J. Cho, M. Asheghi, H. S. P. Wong and K. E. Goodson, Presented in part at the IEEE Intersociety Conference on Thermal and Thermomechanical Phenomena in Electronic Systems (ITHERM) 2014, Orlando, FL, USA, May 27-30, 2014.

9 J. Y. Wu, M. Breitwisch, S. Kim, T. H. Hsu, R. Cheek, P. Y. Du, J. Li, E. K. Lai, Y. Zhu, T. Y. Wang, H. Y. Cheng, A. Schrott, E. A. Joseph, R. Dasaka, S. Raoux, M. H. Lee, H. L. Lung, C. Lam and I. M. P. J. Project, 2011 IEEE International Electron Devices Meeting, 2011, 3.2.1-3.2.4.

10 C. Kim, D.-S. Suh, K. H. P. Kim, Y.-S. Kang, T.-Y. Lee, Y. Khang and D. G. Cahill, Appl. Phys. Lett., 2008, 92, 013109.

11 E. Bozorg-Grayeli, J. P. Reifenberg, M. A. Panzer, J. A. Rowlette and K. E. Goodson, IEEE Trans. Electron Devices, 2011, 32, 1281-1283.

12 S. W. Fong, A. Sood, L. Chen, N. Kumari, M. Asheghi, K. E. Goodson, G. A. Gibson and H. S. P. Wong, J. Appl. Phys., 2016, 120, 2201-2665.

13 M. N. Luckyanova and G. Chen, Science, 2012, 338, 936-939. 14 S. Kwon, M. C. Wingert, J. Zheng, J. Xiang and R. Chen, Nanoscale, 2016, 8, 13155-13167.

15 J. C. Caylor, K. Coonley, J. Stuart, T. Colpitts and R. Venkatasubramanian, Appl. Phys. Lett., 2005, 87, 023105.

16 J. H. Kim, Y. C. Jung, S. H. Suh and J. S. Kim, J. Nanosci. Nanotechnol., 2006, 6, 3325-3328.

17 E. S. Landry, M. I. Hussein and A. J. H. Mcgaughey, Phys. Rev. B: Condens. Matter Mater. Phys., 2008, 77, 998-1002.

18 J. E. Turney, E. S. L. Ry, A. J. H. Mcgaughey and C. H. Amon, Phys. Rev. B: Condens. Matter Mater. Phys., 2009, 70, 77157722.

19 Y. Chalopin, K. Esfarjani, A. Henry, S. Volz and G. Chen, Phys. Rev. B: Condens. Matter Mater. Phys., 2012, 85, 10771082.

20 A. J. H. Mcgaughey and M. Kaviany, Int. J. Heat Mass Transfer, 2004, 47, 1799-1816.

21 B. W. van Beest, G. J. Kramer and R. A. van Santen, Phys. Rev. Lett., 1990, 64, 1955-1958.

22 M. Matsui, Mineral. Mag., 1994, 58, 571-572.

23 L. Chen, Z. Huang and S. Kumar, RSC Adv., 2014, 4, 3585235861.

24 W. M. Brown, P. Wang, S. J. Plimpton and A. N. Tharrington, Comput. Phys. Commun., 2011, 182, 898-911.

25 S. Plimpton, J. Comput. Phys., 1995, 117, 1-19.

26 L. Chen, X. Wang and S. Kumar, Sci. Rep., 2015, 5, 12763.

27 J. D. Gale, J. Chem. Soc., Faraday Trans., 1997, 93, 629-637.

28 H. R. Seyf and A. Henry, J. Appl. Phys., 2016, 120, 061605.

29 P. K. Schelling, S. R. Phillpot and P. Keblinski, Phys. Rev. B: Condens. Matter Mater. Phys., 2002, 65, 144306.

30 H. C. Chien, D. J. Yao, M. J. Huang and T. Y. Chang, Rev. Sci. Instrum., 2008, 79, 054902. 
31 T. Yamane, N. Nagai, S. Katayama and M. Todoki, J. Appl. Phys., 2002, 91, 9772-9776.

32 A. J. Griffin Jr, F. R. Brotzen and P. J. Loos, J. Appl. Phys., 1994, 75, 3761-3764.
33 R. M. Costescu, D. G. Cahill, F. H. Fabreguette, Z. A. Sechrist and S. M. George, Science, 2004, 303, 989-990.

34 Y. Zhou, Z. X. Guo, H. Y. Cao, S. Y. Chen, H. J. Xiang and X. G. Gong, Nanoscale, 2016, 8, 17815. 